\title{
Investigation of the track width-dependent melt pool characteristics during laser-sintering of polyamide 12 in correlation to various focus diameters
}

\author{
Lars Meyer $^{1} \cdot$ Gerd Witt $^{1}$
}

Received: 7 January 2020 / Accepted: 26 February 2020 / Published online: 10 March 2020

(c) The Author(s) 2020

\begin{abstract}
Factors such as not only costs, production time, reproducibility, but also the quality of the components are decisive factors in assessing the economic efficiency of a manufacturing process. With additive manufacturing processes, component production is made possible directly from a 3D CAD model. This means that small series and prototypes can already be produced economically today. In this area, the laser-sintering process, in particular, offers great potential for series production due to its high strength values and ductility. With laser-sintering systems that allow an optical widening of the laser focus, a faster exposure of the component and thus a shortening of the building time is possible. We developed a laser-sintering system whose laser focus diameter is adjustable in its cross-sectional area from 0.47 to $2 \mathrm{~mm}$. The goal for the future is to produce large-area components significantly faster by widening the focus diameter, thus making laser-sintering more productive. In this paper, the focus-dependent melt pool formation is examined in correlation to different hatch distances during the laser-sintering of polyamide 12. For this purpose, a test specimen was developed which can display single tracks as well as a multitude of different track widths for all feasible focus level variations. This knowledge is required to determine and investigate the track width-dependent melt pool formation as a function of the focal diameter of the component cross sections.
\end{abstract}

Keywords Laser-sintering $\cdot$ Polyamide $12 \cdot$ Focus diameter $\cdot$ Single track

\section{Introduction}

The additive manufacturing differs from the conventional manufacturing processes by the defined combination of individual volume elements. In laser-sintering, the individual cross sections of the final component are described using scan vectors, which define the later path of the laser focus. The four process steps of preheating, layer generation, lowering of the building platform and powder application are repeated for each layer of components. During layer generation, a scanning system is used to deflect a defined laser beam on a powder bed surface to melt a layer of the component selectively. Different from many additive manufacturing processes, laser-sintering works without supporting

Lars Meyer

lars.meyer@uni-due.de

$1 \quad$ Institut für Produkt Engineering, Lehrstuhl Fertigungstechnik, Universität Duisburg-Essen, 47057 Duisburg, Germany structures so that a component can be placed freely in the entire available space. Several components can, therefore, be nested or placed on top of each other, clearly demonstrating the advantages of the process in terms of productivity compared to other processes.

For the development of advanced exposure parameters, a test system has been set up which can completely represent the laser-sintering process. Special features of the system include the variation of the focus diameter for testing innovative scanning strategies. The aim is to achieve a homogeneous energy input with simultaneously increased productivity. This can be achieved, for example, by targeted defocusing of the laser spot for large-scale component layers.

A detailed study of the energy input by means of a focused laser beam was conducted by Williams and Deckard in [1]. Thus, a maximum possible energy input into the polycarbonate material was found. Many other investigations, for example [2-4], deal with the energy input in the laser-sintering process, but without considering the expansion of the focus diameter. 
The quantities significant for the energy input are declared in [5] as laser power and spot velocity. The investigations are based on a one-dimensional model due to the fast movement of the laser spot and the low thermal conductivity of the material. The simulations show that the interaction time of the overlapping scan vector lines, which are dependent on the beam diameter, correlates with the scan vector length and is thus significantly responsible for the energy introduced into the material. The influence of the spot size is described as small or non-existent, but without providing experimental evidence for this thesis.

In [6], Noeken examines the penetration depth of the laser radiation in single views under different variations of the material polystyrene. The relationship between the energy input and the layer thickness was investigated. An essential result is that the amount of energy applied has a significant influence on the layer thickness. The investigations were only carried out with a constant laser spot diameter, which is why the variables were defined by the laser power, the hatch distance and the scanner speed.

The topic of energy input by means of laser radiation within the laser-sintering process is dealt with in detail by Keller in [7]. The results show that the process variables of laser power, spot velocity, hatch and preheat temperature are significant parameters for a defined working range. This working range takes into account the temperature distribution in the cross section and is formulated as a model in the form of a required minimum cooling time between the scan vectors. Although Keller deals with beam caustics and describes an expanded beam diameter by shifting the focal plane, the effects on the process are not further investigated.

Various state-of-the-art solutions are already being developed to increase the productivity of systems used in additive manufacturing. In the field of metal processing, there are up to four lasers installed within one system [8, 9]. In the field of plastic processing, system manufacturers also responded to customer requests for increased productivity by increasing the number of lasers within a system. For example, with an EOS P7 or P5 system, two lasers operate simultaneously and independently of each other, so that productivity was almost doubled compared to systems with one laser $[10,11]$. 3D Systems provide an alternative to the multiple laser. Using digital scanner systems, the scanning speed of the laser spot is increased. The use of laser spot speeds of up to $12.7 \mathrm{~m} / \mathrm{s}$ is possible [12].

The SLM 280 2.0 Selective Laser Melting Machine also uses a defocusing unit to expand the laser focus [13]. However, this measure can only be used to a very limited extent in the process since the laser power is not sufficient for largearea defocusing.

To tap the potential of defocusing in laser-sintering, new exposure parameters must be developed. These parameters should be able to significantly reduce the exposure time for larger component areas and at the same time enable homogeneous properties of the component.

\section{Methods}

The methodology is based on the use of a specially developed test specimen. The test sample is described by a $2-\mathrm{mm}$ stable base body, which is holding the single tracks in position. The distance between the individual tracks orientated parallel to each other increases by $10 \%$ from $0.2 \mathrm{~mm}$ to up to $3.27 \mathrm{~mm}$.

In total, one test specimen was produced and evaluated for each of the eleven focus levels that could be achieved. Each sample, regardless of its focus level, receives a single laser track at the end of the sample, which is generated with a spacing of $6.7 \mathrm{~mm}$ and isolated from other individual lines. This means that a total of 29 individual tracks can be used to ensure sufficiently accurate observation of the available track width spacings (see Fig. 1).

Eleven different focus levels from 0 to 10 were implemented, with focus level 0 describing the minimum and focus level 10 the maximum resulting focus diameter. To realize the enlarged focus diameter, the focus position was shifted using a dynamic defocusing unit. The linear displacement of a lens $z_{1}$ results in a non-linear widening of the focus diameter $w\left(z_{1}\right)$ according to the beam waist (see Eq. 1). In addition, the resulting focus diameter depends on the input beam diameter $w_{0}$, which is also variable with the laser power used $[14,15]$.

$w\left(z_{1}\right)=w_{0} \times\left[1+\left(\frac{z_{1}}{z_{\mathrm{R}}}\right)^{2}\right]^{\frac{1}{2}}$

with $Z_{\mathrm{R}}=$ Rayleigh length.

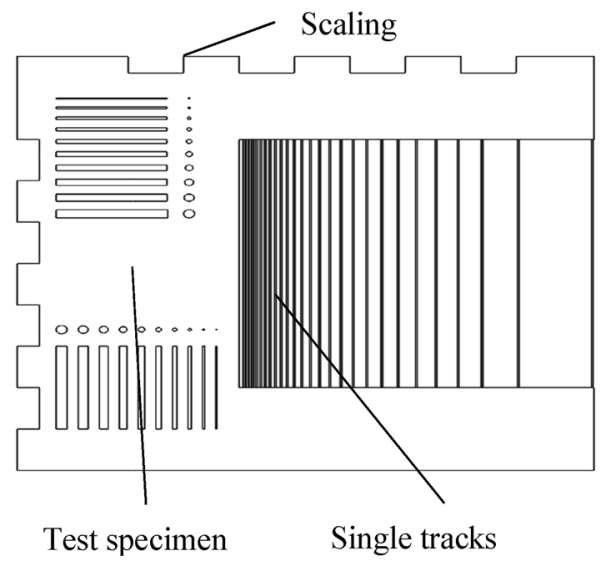

Fig. 1 Test specimen 
Due to the manifold influences on the resulting focus diameter, it is not possible to give precise information about the theoretical focus diameter. According to the decrease in beam intensity $\left(1 / \mathrm{e}^{2}\right)$, the focus diameter measured for the Gaussian beam is a minimum of $0.47 \mathrm{~mm}$ and a maximum of $2 \mathrm{~mm}$. The laser power used for the different focus levels amounts to $35 \mathrm{~W}$ at focus level 0 to $131.3 \mathrm{~W}$ within focus level 10 and was determined in preliminary investigations and on the basis of the adapted scanner speed of $4 \mathrm{~m} / \mathrm{s}$ in comparison to the selected supporting point (compare Table 1). The preliminary investigations are based on the observation of the exceeding of the degradation limit during the production of various test specimens as well as the incremental adjustment of the laser power in the process. This results in increasing values of the laser power, which were assigned to the focus levels according to Table 1 .

The focus speed was kept constant at $4 \mathrm{~m} / \mathrm{s}$, which corresponds to the maximum value of the scanner system under consideration of the aperture and is aimed at increasing productivity. The layer thickness used is constantly at $0.1 \mathrm{~mm}$.

One test specimen was also produced on an EOS Formiga P100 using the standard parameter "mechanic" at $176^{\circ} \mathrm{C}$ installation space temperature and a layer thickness of $0.1 \mathrm{~mm}$, a laser power of 21 watts and a scanner speed of $2.5 \mathrm{~m} / \mathrm{s}$ as a supporting point. Thus, a direct comparison with a commercial system can be made, which can be used for the correct evaluation and interpretation of the samples.

The test specimens for each focus stage were evaluated according to the resulting track width, the penetration depth and the energy density resulting from the varying track widths. The aim is to determine the necessary track width distance for the generation of a homogeneous melt pool as a function of different focus levels and work out the basis for the generation of three-dimensional components with a widened focus.

Due to the fact that the individual tracks are sensitive to mechanical influences, a photo documentation of the individual tracks was created and measured by software using a reference dimension. A Canon EOS 40D SLR camera and an Olympus BX-51 light microscope were used for this purpose. To determine the penetration depth, the samples were embedded in epoxy resin, cross sections were made, documented and evaluated. All specimens were manufactured with a 50\% refreshed PA 2200 powder from EOS. To protect the sensitive individual tracks, the specimens were blasted with glass pearls under a reduced pressure of $\sim 2-2.5$ bar, which can lead to individual particles adhering to the specimens.

\section{Results}

The evaluation of the individual tracks depends on the focus level used. Significant values are given by the width of the single track, the track width distance at the beginning of a homogeneous melt pool and the resulting volume energy density.

The evaluation of the individual tracks shows a reproducible result in two test series with regard to the resulting track width with the exception of the highest focus stage (see Fig. 2). The individual track widths of the focus levels 0 to 10 determined with the microscope can be seen. Up to focus level 3 , the width of the individual track undergoes only minor changes and is in the range of $0.55-0.8 \mathrm{~mm}$ with relatively strong variations. From focus level 4, the track width changes significantly up to the highest focus level. An exception to this is the second test series, in which only marginal changes in track width were visible between focus levels 9 and 10. The smallest track width of $0.55 \mathrm{~mm}$ is in focus stage 2 of test series 1 and is thus at the same level as

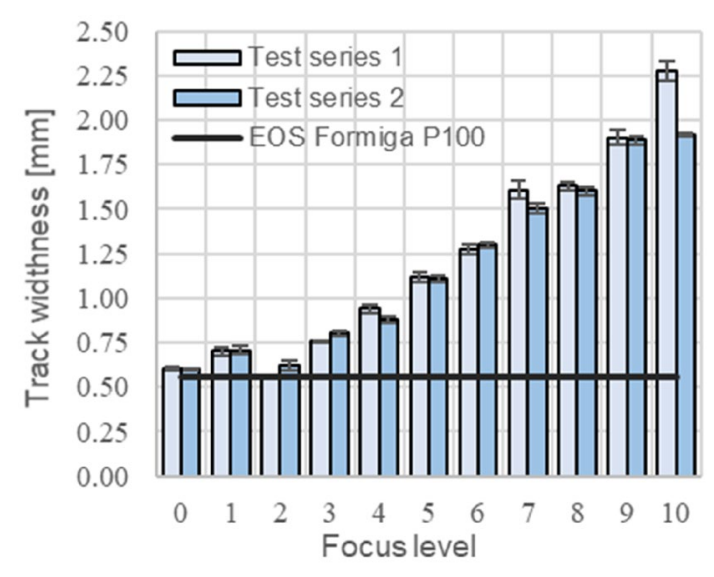

Fig. 2 Width of the single tracks

Table 1 Parameters at testing machine with focus and laser power $P_{\mathrm{L}}$

\begin{tabular}{llllllr}
\hline Focus & 0 & 1 & 2 & 3 & 4 & 5 \\
\hline$P_{L}[\mathrm{~W}]$ & 35 & 43.5 & 46.4 & 58.6 & 62.2 & 80.2 \\
\hline Focus & 6 & 7 & & 8 & & 9 \\
\hline$P_{\mathrm{L}}[\mathrm{W}]$ & 91.6 & 106.7 & & 116.3 & 130.3 & 131.3 \\
\hline
\end{tabular}


the EOS Formiga P100. With a value of $2.28 \mathrm{~mm}$ on focus level 10, the largest track width is also within test series 1 .

The results show a partly unexpected behavior in low focus levels. The reduction of the track width within focus stage 2 may indicate a performance-specific behavior of the acousto-optical modulator (AOM), which is installed in the test system. Reliable track width variations are, therefore, possible in the range between $0.6 \mathrm{~mm}$ in focus stage 0 and $1.9 \mathrm{~mm}$ in focus stage 9 . All individual tracks show a comparatively constant penetration depth of approximately $150 \mu \mathrm{m}$ in the smallest focus to $220 \mu \mathrm{m}$ in focus stage 10 . This effect can be attributed to the extended interaction time of the focus diameter on a single particle.

The evaluation of the test specimen from the commercial machine shows a single track width of $0.553 \mathrm{~mm}$. During the evaluation of the supporting point, it is noticeable that a homogeneous melt pool is already present from a track width distance of $0.43 \mathrm{~mm}$. When considering the individual track width, this observation is plausible, whereby the resulting volume energy density corresponds to only $0.196 \mathrm{~J} / \mathrm{mm}^{3}$. In comparison to the standard process parameters, where the volume energy density $\mathrm{E}_{\mathrm{V}}=0.35 \mathrm{~J} / \mathrm{mm}^{3}$ is used, the difference is clearly visible. The deviation between the standard track spacing of $0.25 \mathrm{~mm}$ is very significant and suggests that a correction factor for visible homogeneous layer formation is necessary for successful layer generation. A homogeneous melt pool is shown in Fig. 3 as zone III. Only from this range of defined hatch distances is it no longer possible to detect a single track. The start of the homogeneously pronounced melt pool can also be easily detected with small focus diameters. In zone I, there are clearly defined individual lines, while zone two is a mixed area of connected individual lines. Finally, from zone III there is a homogeneous melt bath in which no individual lines are visible. To determine the resulting hatch distance, the individual lines of each focus level are counted so that a comparison with the lines in the CAD model is possible (cf. numbers 1, 5 and 10 in Fig. 3).

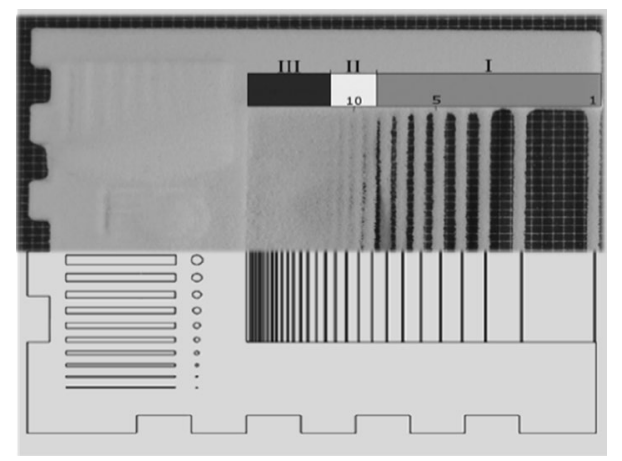

Fig. 3 Measurement of the test specimen of focus level 5
The validation of this procedure is to be carried out with the evaluation of the smallest focus stage on the test facility. In comparison to the Formiga, a single track of $0.6 \mathrm{~mm}$, approximately $0.05 \mathrm{~mm}$ wider, was found in the test facility at focus level 0 . Also with this sample, the track width distance, which apparently leads to a homogeneous melt pool, can be found at a high track width distance of $0.457 \mathrm{~mm}$. The resulting energy density amounts to $0.192 \mathrm{~J} / \mathrm{mm}^{3}$ and thus deviates by only $2 \%$ from the support point.

Due to the reproducible results of the commercial and the research plant, a correction factor is introduced to be able to determine the process-safe track width distance directly from the beginning homogeneous melt pool. The correction factor is the quotient of homogeneous melt pool and the recommended process parameter for the hatch distance of $0.25 \mathrm{~mm}$ of the commercial plant. Thus, the dimensionless correction factor of 0.591 applies, which can be used directly to determine the adjustable plant parameter as a function of the apparently determined first homogeneous melt pool formation.

By evaluating the homogeneous melt pool, the track width distance for successful layer generation can be determined with the aid of the specific correction factor. The results of the expected track width distances can be seen in Fig. 4 . The realizable hatch distances are, therefore, in the range of $0.27-0.85 \mathrm{~mm}$.

As it can be seen, the results of the homogeneous layer generation and the results of the individual tracks show a very similar course. This indicates a correct evaluation of the individual tracks, although their handling was made considerably more difficult due to the filigree individual tracks.

The resulting system parameters will in the following be checked with the cross sections of the individual tracks. The penetration depth, i.e., the single-layer thickness generated, is decisive for successful layer generation. Depending on the material, the thickness of the single-layer should be 1.5-2.5

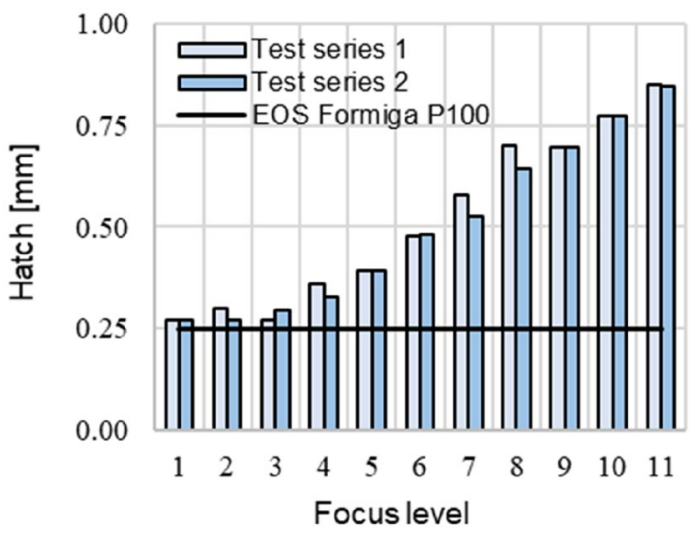

Fig. 4 Resulting hatch distance 
times the thickness of the machine, so that a high-quality fusion with the underlying layer can be achieved [16].

A further criterium for the evaluation of the layer connection is the consideration of the cross-sectional shape. Since the intensity distribution of the laser beam corresponds to a gaussian distribution, it is expected that the resulting cross section of the individual track will reflect this intensity distribution (see Fig. 5). Three representative focus levels of focus 0 , focus 5 and focus 10 are shown.

It can be seen that the influence of the cross-sectional shape continuously decreases with larger focus levels. The thickness of the individual tracks and the resulting melt pool remains comparatively constant and is between 0.15 and $0.22 \mathrm{~mm}$, which indicates an adequate energy input. The shape of the individual track does not change significantly

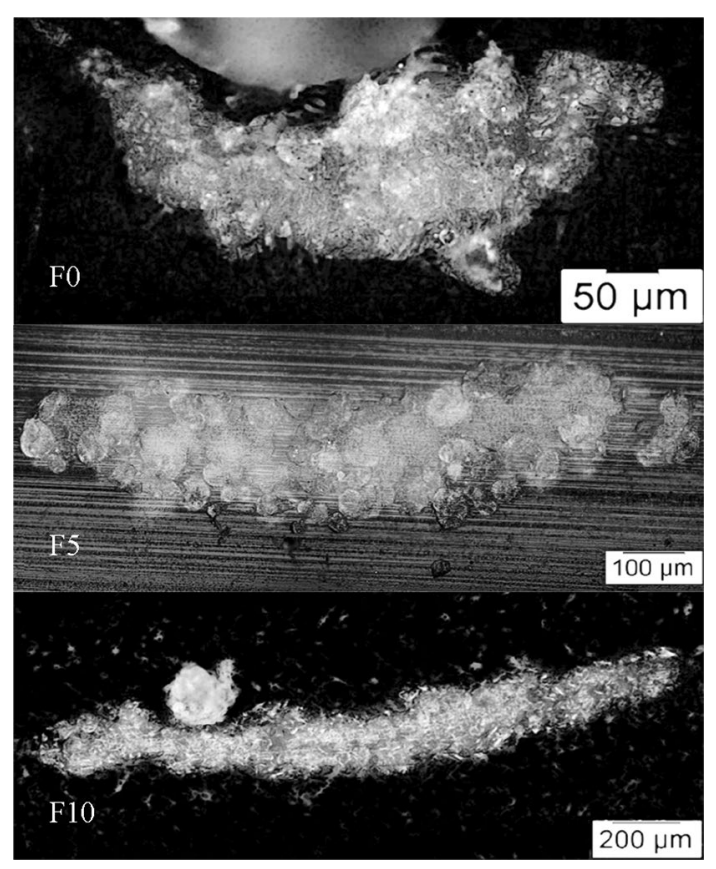

on the side surfaces, so that a continuous overlap to form a homogeneous melt pool can be assumed for a wider individual track. The penetration depth of the melts can be measured at higher focus levels up to $0.405 \mathrm{~mm}$, without visible degradation effects.

This observation suggests that with an expanded focus more energy can be introduced into the material without thermally damaging it.

In the next study, the samples embedded in epoxy resin were cut in the middle perpendicular to the individual lines. Thus, the formation of the melt pool according to zone III in Fig. 3 could be examined for the penetration depth of the laser. The resulting energy density could be observed at defined hatch spacings, which resulted in a reduction of the hatch spacing. Figure 6 shows the resulting energy densities investigated on the basis of three representative focus levels. The focus levels 0,5 and 10 are considered.

The energy density of the lowest focus level ranges from 0.14 to $0.3 \mathrm{~J} / \mathrm{mm}^{3}$. The maximum layer thickness thus achieved is $200.3 \mu \mathrm{m}$. After exceeding the energy density of $0.3 \mathrm{~J} / \mathrm{mm}^{3}$, no more precise measurements could be performed at the smallest focus level. This can be caused by the initial decomposition of the material or a distortion of the measurement by embedding the samples. Since the energy densities used are below the energy density of the Formiga P100 $\left(0.34 \mathrm{~J} / \mathrm{mm}^{3}\right)$, a further increase in the achievable layer thickness of up to $220 \mu \mathrm{m}$ can be expected. A significant difference is in the achievable energy densities with increased focus. Layer thicknesses of up to $288 \mu \mathrm{m}$ at focus level 5 and $0.7 \mathrm{~J} / \mathrm{mm}^{3}$ and $400 \mu \mathrm{m}$ at focus level 10 and $0.94 \mathrm{~J} /$ $\mathrm{mm}^{3}$ are determined. The decrease of the layer thicknesses in the larger focus stages can be an indication for degradation effects already occurring and indicates the upper limits of the material-dependent energy input. However, the results show that an increased input of energy into a component cross section is possible by widening the focus diameter by a factor of three.

Fig. 5 Cross-sectional shape of different focus levels

Fig. 6 Layer thickness as a function of energy density

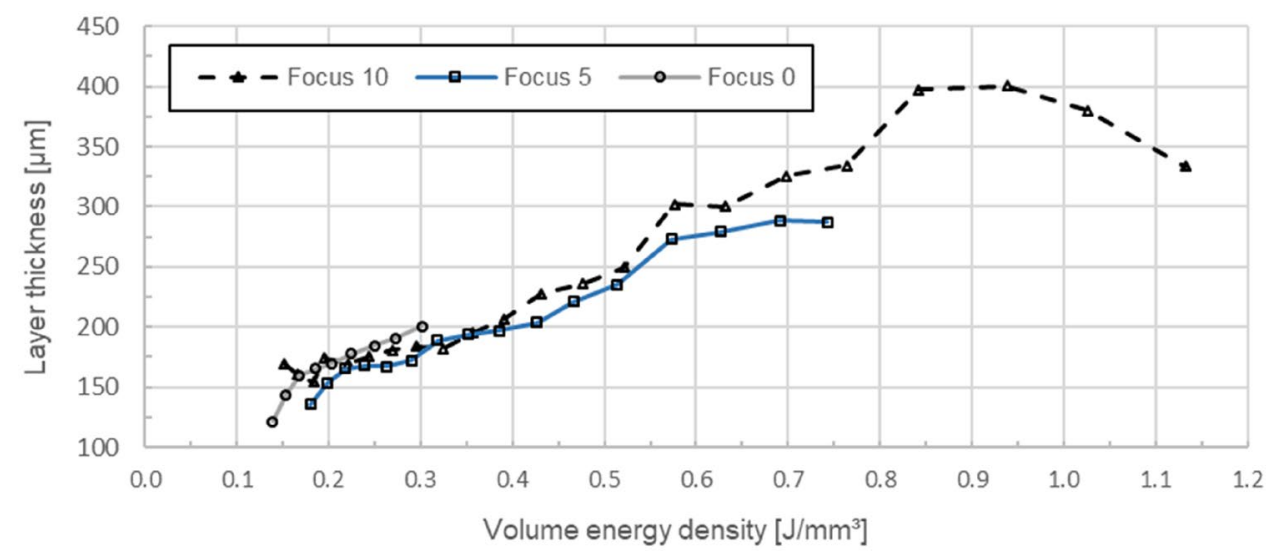




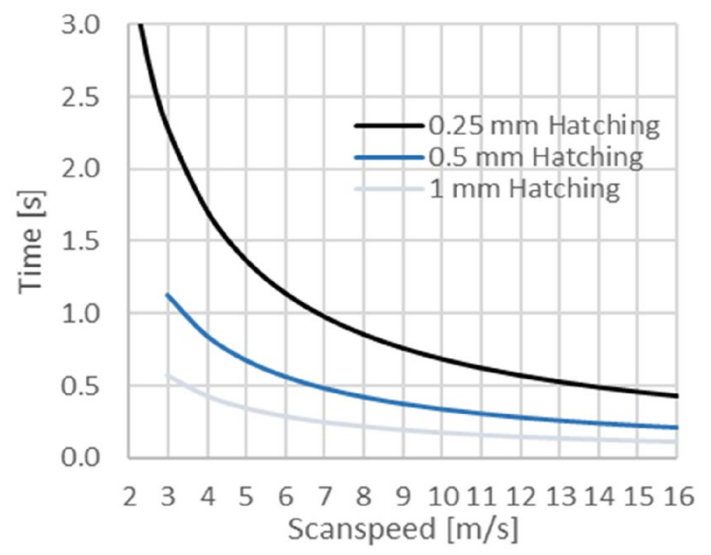

Fig. 7 Scan time for a $170 \mathrm{~mm} \times 10 \mathrm{~mm}$ area

The results show that an acceleration of the process can be achieved by increasing the focus and the resulting machine parameters. It was possible to successfully produce a single track with a width of up to $2.28 \mathrm{~mm}$ as well as a two-dimensional surface with a maximum track width of $0.85 \mathrm{~mm}$. In addition, the appropriate system parameters for the production of three-dimensional components with widened focus diameters could be evaluated.

\section{Discussion}

The generating of the component cross sections has a significant influence on the entire process time. In the state of the art, a focus diameter as small as possible is used in favor of a detailed representation, which allows only a small track width distance. The state of the art was extended with a larger and dynamically variable focus, which can realize a significantly higher track width distance to expose large-area components faster. This paper shows a suitable method for qualifying system parameters for new optical systems. The analysis of the single tracks, as well as the varying hatch distances of a specimen, allows the evaluation of unknown focus diameters on applicable system parameters. The theoretical potential of expanded focus diameters can be seen in Fig. 7. The hatch distance of $0.25 \mathrm{~mm}$ represents the state of the art. The exposure time of a $170 \mathrm{~mm} \times 10 \mathrm{~mm}$ area was used as the base area for the calculation of varying scan line distances since this geometry corresponds to the tensile specimen type $1 \mathrm{~A}$.

The mirrors' inertia, as well as multi-laser concepts, was not further considered. The required time for a $170 \times 10 \mathrm{~mm}^{2}$ area with different hatch distances resulting from the adjustable focus diameter is considered. It can be seen that a reduction of the exposure time is possible by expanding the focus compared to the state of the art.
Successful surface connections with a hatch distance of $0.85 \mathrm{~mm}$, which corresponds to an increase of $240 \%$, were demonstrated in the test.

The actually achievable process accelerations depend, among other things, on the part, the scanner speed, the hatch distance and the scanning strategy. The use of large focus diameters can lead to further process acceleration due to the high penetration depth and new scanning strategies. For example, future fill scan strategies may result in only every second or third layer of a component being exposed, while the contour is produced in every layer. This allows both the level of detail to be maintained and productivity to be increased.

However, it must also be taken into account that an enlarged focus will not always be able to achieve a sufficiently good connection to the contour. A double contour exposure with a focus level between the large focus in the fill area and the finely detailed contour would be conceivable.

Subsequent investigations must deal with the production of three-dimensional components and their properties. The influence of large focus diameters on the component properties must be checked and validated so that fundamental correlations in laser-sintering and new scanning strategies can be derived. In addition, the actual increase in productivity compared to commercial systems must be determined and compared.

Acknowledgements Open Access funding provided by Projekt DEAL. The results of this publication are based from the investigations of the research project HiPer-LS and were funded by the Bundesministeriums für Bildung und Forschung (BMBF) within the framework concept "Forschung für die Produktion von morgen". Responsibility for the contents of this publication is assumed by the authors.

Open Access This article is licensed under a Creative Commons Attribution 4.0 International License, which permits use, sharing, adaptation, distribution and reproduction in any medium or format, as long as you give appropriate credit to the original author(s) and the source, provide a link to the Creative Commons licence, and indicate if changes were made. The images or other third party material in this article are included in the article's Creative Commons licence, unless indicated otherwise in a credit line to the material. If material is not included in the article's Creative Commons licence and your intended use is not permitted by statutory regulation or exceeds the permitted use, you will need to obtain permission directly from the copyright holder. To view a copy of this licence, visit http://creativecommons.org/licenses/by/4.0/.

\section{References}

1. Williams JD, Deckard C (1998) Advances in modeling the effects of selected parameters on the SLS process. Rapid Prototyp J 4(2):90-100 
2. Wegner A, Witt G (2019) Adjustment of isotropic part properties in laser sintering based on adapted double laser exposure strategies. Opt Laser Technol 109:381-388

3. Wörz A, Drummer D Understanding hatch-dependent part properties in SLS. In: Proceedings of the solid freeform fabrication symposium 2018, pp 1360-1369

4. Chalancon A, Bourell D Measured energy densities for polyamide 12 and comparison of values calculated for laser sintering. In: Proceedings of the solid freeform fabrication symposium 2016, pp 2217-2223

5. Nelson JC (1993) Selective laser sintering: a definition of the process and an empirical sintering model, The University of Texas at Austin, Dissertation

6. Nöken S (1997) Technologie des Selektiven Lasersinterns von Thermoplasten, Zugl.: Aachen, Technische Hochschule, Dissertation

7. Keller B (1998) Rapid prototyping. Grundlagen zum selektiven Lasersintern von Polymerpulver, Zugl.: Universität Stuttgart, Dissertation

8. SLM Solutions AG: SLM 800 Selective Laser Melting Machine. Produktdatenblatt, 2017. https://www.slm-solutions.com/filea dmin/user_upload/downloads/en/150EN181102_03_SLM80 0_WEB.pdf. abgerufen am 27 Sep 2019

9. EOS GmbH: M 300Serie. https://cdn.eos.info/8ebe9a797a1d454 4/1b5ae58ed24f/EOS_System_Data_Sheet_EOS_M_300_Serie s_de_WEB.pdf. abgerufen am 27 Sep 2019
10. Systemdatenblatt EOS P500, n.n., 2017

11. EOS GmbH: EOS P 770. https://cdn0.scrvt.com/eos/70a35a17f1 3f2106/5b80ad56118c/EOS_System_Data_Sheet_EOS_P_770_ de_WEB.pdf. abgerufen am 27 Sep 2019

12. 3D Systems: Selektives-Lasersintern-DruckerThermoplastische Produktionsteile gefertigt mit den $\operatorname{ProX}^{\circledR}$ und sPro $^{\text {TM }}$ SLS-Druckern https://de.3dsystems.com/sites/default/files/2019-06/3d-syste ms-sls-printers-tech-specs-a4-de-2019-06-25-web.pdf. abgerufen am 27 Sep 2019

13. SLM Solutions AG: SLM 280 Selectie Laser Melting Machine. Produktdatenblatt, 2017. https://www.slm-solutions.com/filea dmin/user_upload/121EN180808-02-002-SLM280-20_WEB3. pdf. abgerufen am 27 Sep 2019

14. Bliedtner M (2013) Lasermaterialbearbeitung. CARL HANSER Verlag

15. Young M (1997) Optik, laser, wellenleiter. Springer, Berlin

16. Rietzel D (2011) Werkstoffverhalten und Prozessanalyse beim Laser-Sintern von Thermoplasten, Friedrich-Alexander-Universität Erlangen-Nürnberg, Dissertation

Publisher's Note Springer Nature remains neutral with regard to jurisdictional claims in published maps and institutional affiliations. 